\title{
Article \\ Effect of Fiber Content and Silane Treatment on the Mechanical Properties of Recycled Acrylonitrile-Butadiene-Styrene Fiber Composites
}

\author{
Vardaan Chauhan * , Timo Kärki and Juha Varis \\ Department of Mechanical Engineering, LUT University, 53851 Lappeenranta, Finland; timo.karki@lut.fi (T.K.); \\ juha.varis@lut.fi (J.V.) \\ * Correspondence: vardaan.chauhan@lut.fi
}

Citation: Chauhan, V.; Kärki, T.; Varis, J. Effect of Fiber Content and Silane Treatment on the Mechanical Properties of Recycled AcrylonitrileButadiene-Styrene Fiber Composites. Chemistry 2021, 3, 1258-1270.

https://doi.org/10.3390/

chemistry3040091

Academic Editor: Pietro Russo

Received: 4 October 2021

Accepted: 25 October 2021

Published: 1 November 2021

Publisher's Note: MDPI stays neutral with regard to jurisdictional claims in published maps and institutional affiliations.

Copyright: (c) 2021 by the authors. Licensee MDPI, Basel, Switzerland. This article is an open access article distributed under the terms and conditions of the Creative Commons Attribution (CC BY) license (https:// creativecommons.org/licenses/by/ $4.0 /)$.

\begin{abstract}
The aim of the present study was to investigate the effects of fiber content and then silane treatment on the mechanical performance of the natural fiber composites of recycled acrylonitrilebutadiene-styrene (ABS) provided by the automotive sector. Wood and palmyra fibers were used as fillers in $10 \%$ and $20 \%$ fiber content composites. The fibers were treated with $N$-(2-Aminoethyl)3-aminopropyltrimethoxysilane to improve the interfacial adhesion between fibers and polymer matrices. The mechanical properties of the composites were determined by tensile and impact tests. Morphological analysis was later performed using a scanning electron microscope (SEM). According to the experiment results, the tensile and impact strength of both wood and palmyra fibers increase after silane treatment. However, for the low-wood-fiber-content composite, the tensile and impact strength decrease after silane treatment due to the presence of an excess amount of silane relative to fiber content. The addition of wood and palmyra fibers significantly improved the tensile modulus of composite material and further increases slightly after silane treatment. Finally, SEM analysis shows a homogenous mix of fibers and polymer matrices with fewer voids after silane treatment, thereby improving interfacial adhesion.
\end{abstract}

Keywords: recycled ABS; natural fibers; mechanical properties; automotive

\section{Introduction}

Acrylonitrile-butadiene-styrene (ABS) is one of the most used thermoplastic terpolymers. It is prepared by polymerizing styrene and acrylonitrile in the presence of polybutadiene [1-3]. Acrylonitrile offers heat and chemical resistance, while butadiene provides impact resistance and styrene provides processability and surface properties [4-6]. Thus, ABS terpolymer exhibits good mechanical properties, easy processing, chemical resistance, good surface appearance, and recyclability $[1,3,4,7,8]$. ABS is widely used in electrical and automotive applications such as household appliances, automobile body parts, and wheel covers $[1,5,9]$. Due to the widespread applications, a large volume of ABS is also available in the form of post-consumer polymer waste after the end of life of its applications. This post-consumer polymer waste is utilized as an aggregate in concrete and road construction [10-12] as well as a matrix material in natural fiber polymer composites (NFPCs).

NFPCs are composed of natural fibers as a reinforcement/filler material and a polymer matrix. NFPCs are used as an alternative material in furniture, automotive parts, window panels, household equipment, and decking $[8,13,14]$. Previous studies related to ABS as a polymer matrix in NFPCs primarily focused on using virgin ABS [2,3,7,13,15-17]. However, recycled ABS extracted from automotive or electrical waste streams can also be utilized in making composite materials. Additionally, due to strict legislation in European and several Asian countries regarding waste from electrical and electronic equipment and automotive end-of-life requirements, product manufacturers need to consider the 
environmental impact of materials used in manufacturing goods [18,19]. Therefore, the material recovered from such high-value waste streams can easily be reused in other applications or even in similar ones.

One main issue with using recycled ABS or any other polymer extracted from postconsumer applications is that these polymers are not free of impurities which are either caused by their usage during the product life cycle or due to mixing during the collection process. These impurities lead to detrimental effects on the mechanical properties of the recycled material and change the thermal characteristics of the material [20]. Studies have also found that with even $1 \mathrm{wt}$ \% of impurities in the polymer material, the properties' reduction was severe and unacceptable when compared to virgin polymer material [21,22].

Natural fibers are derived from plant, animal, and mineral sources. Plant fibers such as wood, hemp, kenaf, sisal, flax, palm, and jute are commonly used for reinforcement in composites. Wood is the most common plant fiber used as a filler in NFPC materials. However, the choice of a natural fiber as a filler in NFPCs largely depends on the source proximity; for example, jute and palm are commonly used in Asia, whereas in Europe wood and hemp are the most common. Furthermore, for wood fibers the type of source wood can differ drastically from one species of tree to another, which can also affect the overall properties of NFPC materials [23]. In Europe, spruce is the most common type of wood fiber used in composites. On the other hand, palmyra is very economical and widely cultivated in tropical regions of Africa and Asia for its usage in over 800 applications. Palmyra fibers are extracted from the leaf stalks of the palmyra tree and used in producing ropes, painting brushes, broom bristles, fans, baskets, mats, and hats. Due to their low cost and abundance, these fibers could easily be utilized as fillers in NFPC materials [24-26]. The chemical composition of both spruce wood and palmyra fiber is shown in Table 1.

Table 1. Chemical composition of spruce and palmyra fibers.

\begin{tabular}{ccc}
\hline & Spruce [27] & Palmyra [24] \\
\hline Cellulose (\%) & 42.00 & 58.58 \\
Hemicellulose (\%) & 27.30 & 22.80 \\
Lignin (\%) & 27.40 & 13.48 \\
Extractives and Wax (\%) & 2.00 & 0.53 \\
\hline
\end{tabular}

The main issue with NFPC materials is the incompatibility of fibers and polymer matrices. This is due to difference between the hydrophilic nature of fiber and hydrophobic nature of polymers, which results in weak interfacial adhesion [1,13,15-17]. Surface modification methods, such as silane treatment of natural fibers, can improve interfacial adhesion, thus improving the properties of composite materials $[1,4,15-17,28]$. Other surface modification methods include alkaline treatment [29], acetylation [30], enzyme treatment [31], plasma treatment [32], and grafting [33]. The introduction of silane reduces the hydroxyl groups of natural fibers and thus improves interfacial adhesion [34]. For example, Wang et al. [28] studied the effects of silane treatment on the mechanical properties and thermal behavior of bamboo-fiber-reinforced polypropylene composites, and they found that the tensile and flexural strength of silane-treated fibers composites were increased compared to the composition of untreated fibers. However, during the silane treatment silane monomers can also undergo a self-condensation, where they form polysiloxane molecules by reacting with each other, and these molecules are less reactive [35]. As observed by Orue et al. [36], who studied the effect of alkaline and silane treatment on the mechanical properties of sisal fiber/poly(lactic acid) composites, untreated fiber composites and silanetreated fiber composites exhibit low mechanical properties compared to alkaline-treated and alkaline + silane-treated composites at varying fiber contents.

Mechanical properties of NFPCs with ABS as the polymer matrix have been extensively investigated by various research groups across the world. Neher et al. [2,37] examined the mechanical and physical properties of ABS/palm fiber composites and concluded that the tensile strength and flexural strength of the composite material decrease with 
the introduction of fiber content, but that the stiffness of the material increases. Similarly, Martins et al. [38] observed that the introduction of fiber content considerably increases the stiffness of ABS/textile fiber composite materials. Chotirat et al. [15] investigated the mechanical properties of ABS/wood sawdust composites and observed that increasing the wood sawdust content in the composite material increases the modulus but reduces the strength of the material. They also found that a low concentration of silane treatment can improve mechanical properties while a higher percentage has an adverse effect on them. However, most of the previous studies had been focused on virgin polymer materials, and not much focus has been given to prospects of using recycled polymer material in composite manufacturing. Therefore, in this study the effects of fiber content and silane treatment on the mechanical properties of recycled ABS composites containing wood and palmyra fibers were investigated. The main objective of the study was to study how mechanical properties are influenced by silane and varying fiber contents and to identify suitable composite compositions for future automotive applications. The mechanical properties were examined using tensile and impact testing. Furthermore, a scanning electron microscope (SEM) was used to analyze the tensile-fractured surfaces of the composites.

\section{Materials and Methods}

\subsection{Materials}

The waste polymers, primarily consisting of ABS and other styrene-based polymers such as ABS + Polymethyl methacrylate (PMMA), ABS + Polystyrene (PS), ABS + Styrene acrylonitrile resin (SAN), ABS + Acrylonitrile styrene acrylate (ASA), and ABS + Acrylonitrile ethylene styrene (AES) were supplied by Oili Jalonen Oy (Finland) and Majava Group Oy (Finland). These waste materials were extracted from automotive, motorbike, and truck polymer parts such as motorbike frontal fairings, side fairings, tank covers, truck bumpers, car emergency triangle reflectors, and door panels, as shown in Figure 1. The composition of the recycled polymers is shown in Table 2 . The density and melt flow indices of the recycled ABS mixture (R-ABSmix) were $1032 \mathrm{~kg} / \mathrm{m}^{3}$ and $14.98 \mathrm{~g} / 10 \mathrm{~min}$, respectively.

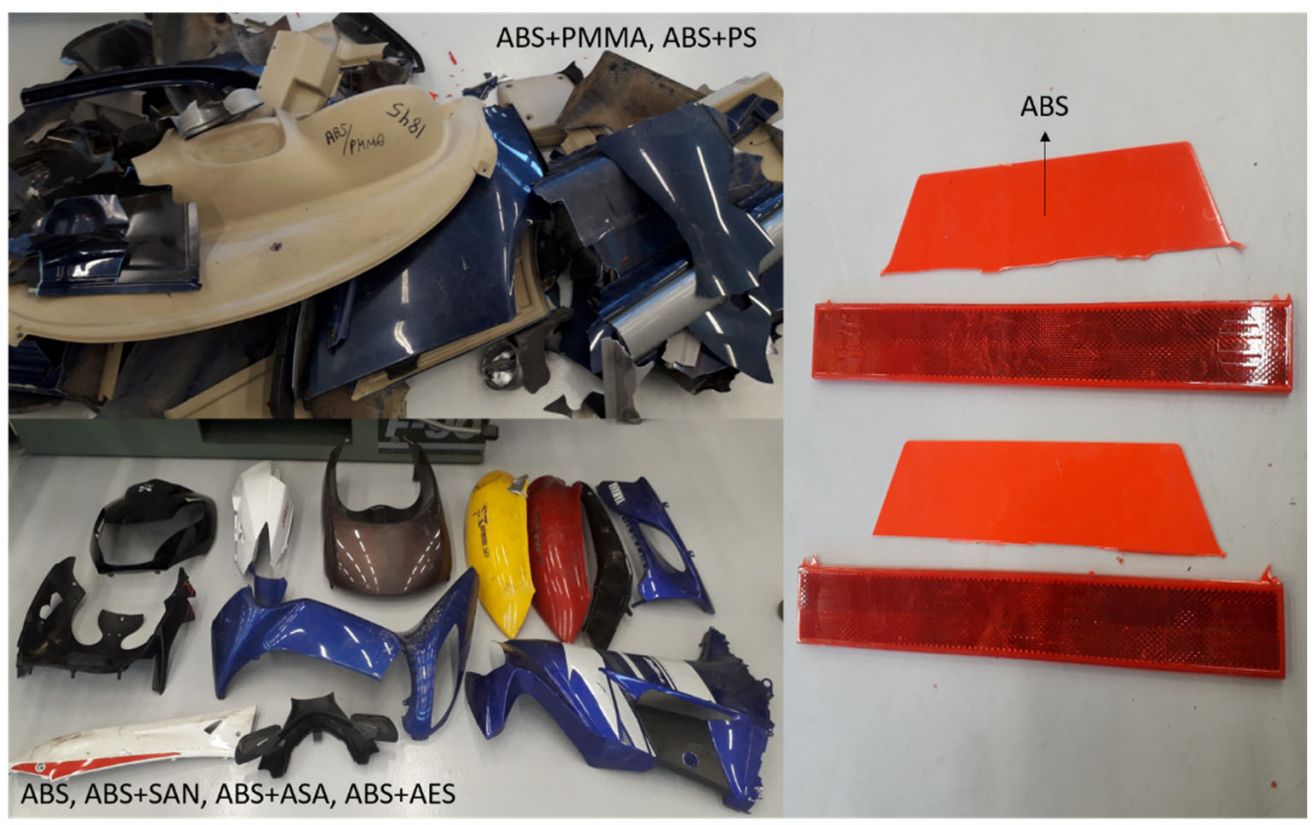

Figure 1. Scrap polymers from various automotive parts. 
Table 2. Composition of recycled polymers.

\begin{tabular}{ccc}
\hline Polymer Type & Weight $\mathbf{( k g )}$ & Composition (\%) \\
\hline ABS & 63.47 & 80.77 \\
ABS + SAN & 1.38 & 1.75 \\
ABS + ASA & 3.62 & 4.61 \\
ABS + AES & 1.25 & 1.59 \\
ABS + PMMA & 6.04 & 7.69 \\
ABS + PS & 2.82 & 3.59 \\
Total & 78.58 & \\
\hline
\end{tabular}

The wood fiber was obtained from Stora Enso Oy, and palmyra (bassine fiber) was obtained from Mirja Dahl Ky (Finland). The fiber size used for composite preparation was less than $1 \mathrm{~mm}$ for both fibers, as shown in Figure 2. The density of wood fiber and palmyra fiber was $457 \mathrm{~kg} / \mathrm{m}^{3}$ and $365 \mathrm{~kg} / \mathrm{m}^{3}$, respectively. In addition, the moisture content for wood and palmyra fibers was $12 \%$ and $10 \%$, respectively. The lubricant used was STRUKTOL ${ }^{\circledR}$ TPW 113, and N-(2-Aminoethyl)-3-aminopropyltrimethoxysilane was used for the surface treatment of fibers.
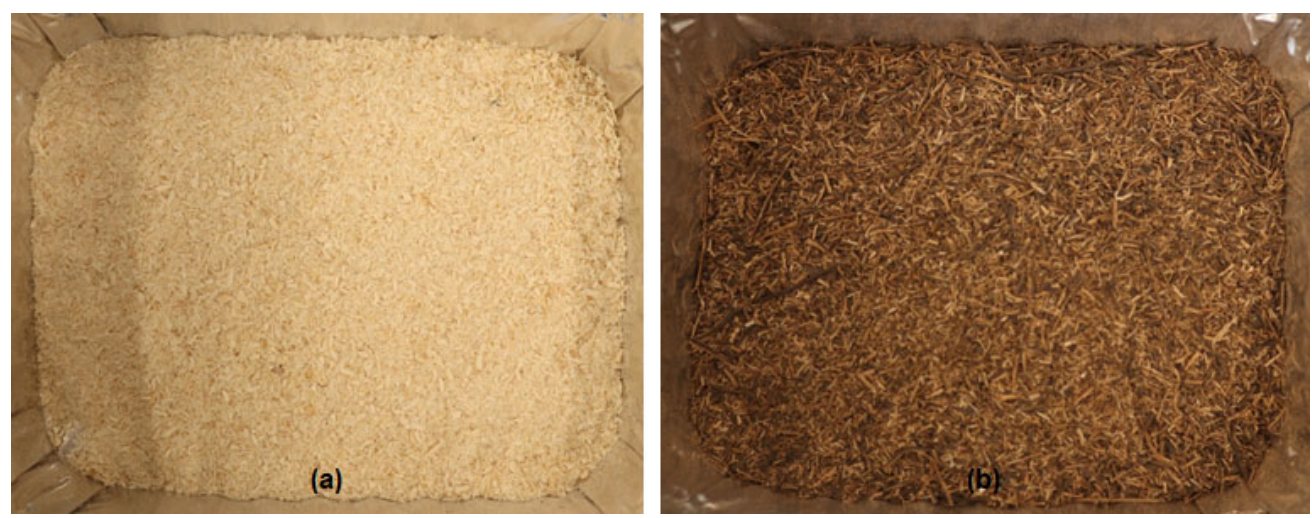

Figure 2. (a) Sample of wood fibers. (b) Sample of palmyra fibers.

\subsection{Silane Treatment}

Both wood and palmyra fibers were treated with 3\% (w/w) N-(2-Aminoethyl)-3aminopropyltrimethoxysilane. The most common method used for silane treatment is immersing the fibers in the silane solution [28,39]. However, since the fiber size was small, a spraying method was chosen, which is a relatively easy way to conduct fiber treatment with silane [40]. In this method, a thin layer of fibers was placed on a silicone sheet as shown in Figure 3 and sprayed with a silane solution using a handheld pump sprayer [35]. The spraying method is preferred over soaking the fibers in the silane because it ensures an even distribution of silane and controls the amount of silane in the material. Afterward, the mixture was dried for $30 \mathrm{~min}$ at $50{ }^{\circ} \mathrm{C}$ before making the composite agglomerate. 


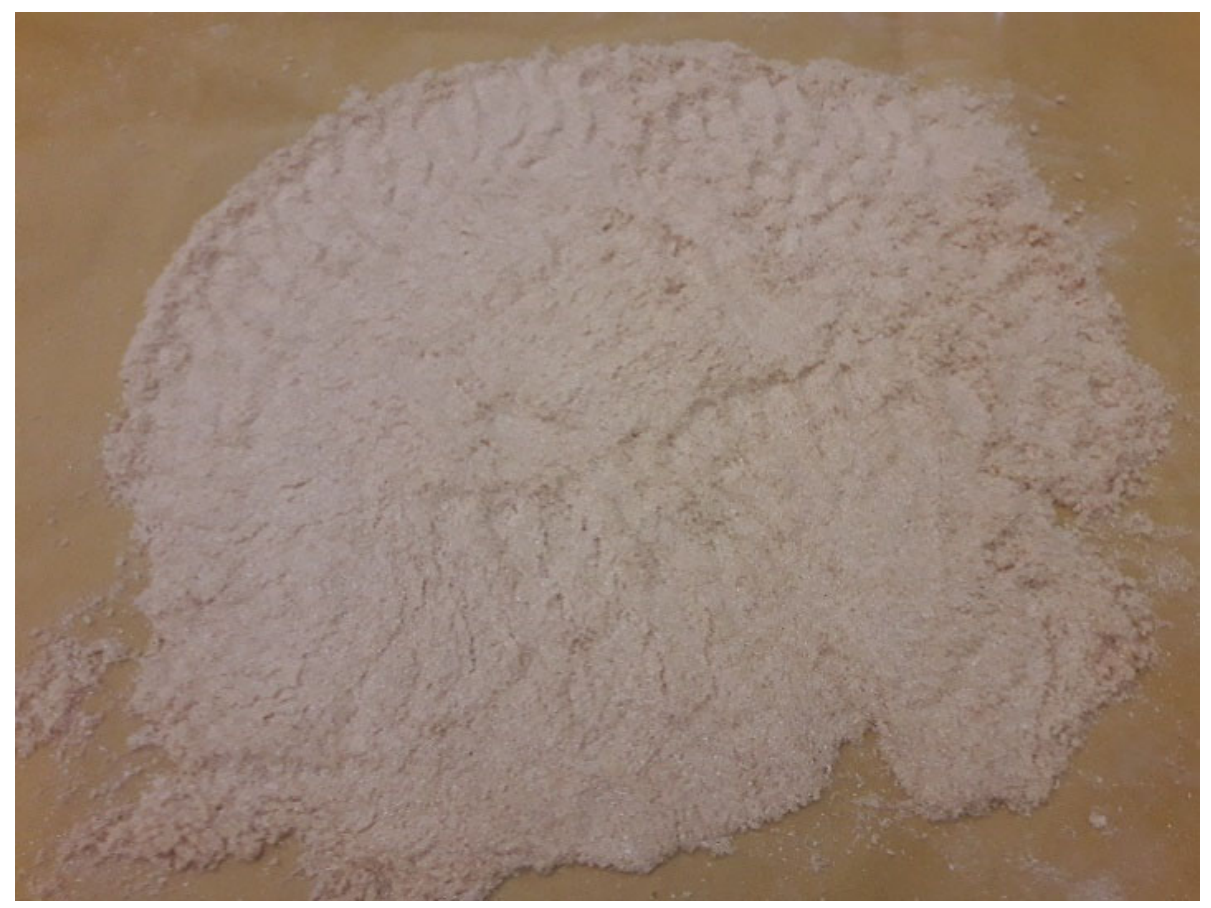

Figure 3. Thin layer of fibers sprayed with silane solution.

\subsection{Composite Preparation}

Both treated and untreated fibers were compounded with polymers using STRUKTOL ${ }^{\circledR}$ TPW 113 3\% $(w / w)$ in Plasmec COMBIMIX-RV /100/200/FV/W. The material composition, density, and designation code for different composite samples are shown in Table 3.

Table 3. Composition of recycled polymer composites.

\begin{tabular}{|c|c|c|c|c|c|c|}
\hline Designation & Fiber & Polymer (\%) & Fiber (\%) & Lubricant (\%) & Silane (\%) & $\begin{array}{l}\text { Density } \\
\left(\mathrm{kg} / \mathrm{m}^{3}\right)\end{array}$ \\
\hline R-ABS/10WF & Wood & 87 & 10 & 3 & - & 1067 \\
\hline R-ABS/10WF-S & Wood & 84 & 10 & 3 & 3 & 1079 \\
\hline R-ABS/20WF & Wood & 77 & 20 & 3 & - & 1074 \\
\hline R-ABS/20WF-S & Wood & 74 & 20 & 3 & 3 & 1083 \\
\hline R-ABS/10PF & Palmyra & 87 & 10 & 3 & - & 1082 \\
\hline R-ABS/10PF-S & Palmyra & 84 & 10 & 3 & 3 & 1068 \\
\hline R-ABS/20PF & Palmyra & 77 & 20 & 3 & - & 1067 \\
\hline R-ABS/20PF-S & Palmyra & 74 & 20 & 3 & 3 & 1087 \\
\hline
\end{tabular}

Initially, the polymer-fiber mixture was first heated in a convection oven at $260{ }^{\circ} \mathrm{C}$ for $20 \mathrm{~min}$. Then, the mixture was transferred into the mold of a Stenhoj 40-ton compression molding machine to produce composite cakes, as shown in Figure 4. The dimensions of composite cakes were $110 \times 110 \times 10 \mathrm{~mm}$. The composite cakes were compressed for a minute in the compression molding machine. After removal from the mold, the composite cakes were air cooled and kept for over $24 \mathrm{~h}$ in a humidifier at $23{ }^{\circ} \mathrm{C}$ and at $50 \%$ relative humidity. 

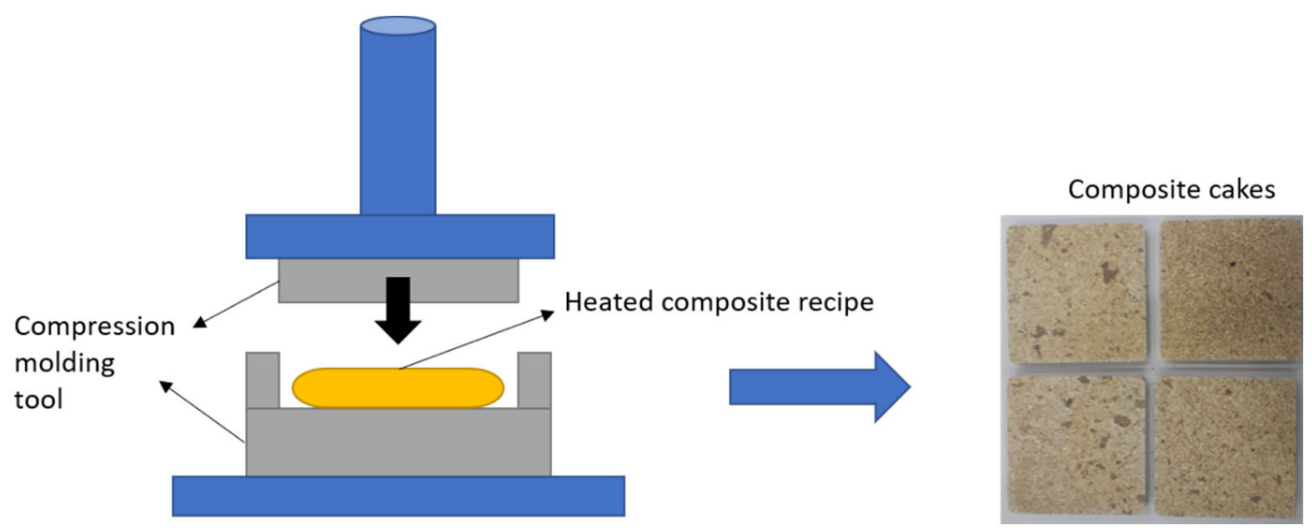

Figure 4. Illustration of the compression molding process.

\subsection{Mechanical Properties Testing}

Composite cakes were cut into the shape of a dog bone for tensile testing according to ASTM D638. The samples were prepared according to type 1 specifications. Ten samples for each composite recipe (overall 8, as shown in Table 3) were prepared for tensile testing purposes and kept in a humidifier for $24 \mathrm{~h}$ at $23{ }^{\circ} \mathrm{C}$ and at $50 \%$ relative humidity. All the composite samples were tested at room temperature for tensile properties using a universal testing machine (Zwick Roell Z020) at a test speed of $2 \mathrm{~mm} / \mathrm{min}$ according to ASTM D638. The experimental data were collected and processed automatically using testXpert II software.

The impact strength of the samples was tested using a Zwick 5102 impact testing machine according to SFS-EN ISO 1791 by using Method ISO $1791 / 1 \mathrm{fU}$. Prior to testing, the samples were prepared according to type 1 test specimens $-80 \pm 2 \times 10 \pm 0.2 \times 4 \pm 0.2 \mathrm{~mm}$, under Charpy unnotched impact strength. Fifteen samples of each composite recipe were prepared and kept for $24 \mathrm{~h}$ at $23{ }^{\circ} \mathrm{C}$ and at $50 \%$ relative humidity in a humidifier before testing. The testing was performed using a pendulum impact tester, with a hammer size of $5 \mathrm{Kpcm}$ for all composite recipes. The Charpy impact strength was calculated according to the equation:

$$
a_{c u}=\frac{E_{c}}{h \times b} \times 10^{3}
$$

where $E_{c}$ is the energy absorbed by test specimen (in joules), $h$ is the thickness of the test specimen (in $\mathrm{mm}$ ), and $b$ is the width (in $\mathrm{mm}$ ) of the test specimen.

\subsection{Surface Morphology Analysis}

The morphology of both wood and palmyra fiber composites before and after silane treatment was examined using a Hitachi SU3500 scanning electron microscope (SEM) at $10.0 \mathrm{kV}$ accelerating voltage using a backscattered electron (BSE) detector. Tensile-fractured specimens of all material samples were examined, and SEM images were obtained at $\times 500$ magnification. All the samples were imaged without coating.

\subsection{Statistical Analysis}

Due to the variation in the observed mechanical properties a statistical analysis of the untreated composite samples with reference to the R-ABSmix material was performed, to see the impact of fiber content on the mechanical properties. Similarly, treated composite recipe results were analyzed with reference to corresponding untreated composite recipes to see the impact of silane treatment on mechanical properties. The statistical analysis was performed in Daniel's XL Toolbox Excel software and by using a one-way ANOVA Bonferroni-Holm post hoc testing algorithm. 


\section{Results}

\subsection{Wood Fiber Composites}

The strength of natural-fiber-reinforced composites is affected by various factors, such as fiber type, fiber length, fiber content, matrix, and interfacial adhesion between fiber and matrix $[2,41]$. The fiber content and effect of silane treatment on the mechanical properties of the wood-fiber-reinforced composites are shown in Table 4. As per the statistical analysis, tensile strength, tensile modulus, and impact strength of both untreated $10 \%$ and $20 \%$ wood fiber composites were found to be significantly impacted. On the other hand, only the tensile strength of treated $10 \%$ and $20 \%$ wood fiber composites was significantly changed and there was no significant change in the tensile modulus values of the silane-treated composites. The impact strength of $10 \%$-silane-treated wood fiber composites also display a significant change, while no significant change was observed in the $20 \%$-silane-treated wood fiber composites. The tensile strength of untreated wood-fiber-reinforced composites decreased with an increase in fiber content. This is mainly attributed to the weak interfacial bonding between wood fibers and the ABS matrix due to the incompatible nature of ABS, which is hydrophobic, and wood fibers, which are hydrophilic. This interfacial bonding strength further decreased with an increase in fiber content in the composite $[15,42]$.

Table 4. Mechanical properties of the wood fiber composites and R-ABSmix.

\begin{tabular}{|c|c|c|c|c|}
\hline & $\begin{array}{c}\text { Tensile Strength } \\
\text { (MPa) }\end{array}$ & $\begin{array}{c}\text { Tensile } \\
\text { Modulus (GPa) }\end{array}$ & $\begin{array}{c}\text { Elongation at } \\
\text { Break (\%) }\end{array}$ & $\begin{array}{c}\text { Impact Strength } \\
\left(\mathrm{kJ} / \mathrm{m}^{2}\right)\end{array}$ \\
\hline R-ABSmix & $16.42 \pm 1.20$ & $1.79 \pm 0.07$ & $1.00 \pm 0.19$ & $5.98 \pm 0.92$ \\
\hline R-ABS/10WF & $9.39 \pm 0.97^{\mathrm{s}}$ & $1.93 \pm 0.11^{\mathrm{s}}$ & $0.48 \pm 0.06$ & $2.90 \pm 0.65^{s}$ \\
\hline R-ABS/10WF-S & $7.98 \pm 1.69^{\mathrm{s}}$ & $1.96 \pm 0.23^{\mathrm{ns}}$ & $0.49 \pm 0.12$ & $2.27 \pm 0.60^{\mathrm{s}}$ \\
\hline R-ABS/20WF & $7.12 \pm 1.66^{\mathrm{s}}$ & $2.05 \pm 0.23^{\mathrm{s}}$ & $0.39 \pm 0.12$ & $2.25 \pm 0.34^{\mathrm{s}}$ \\
\hline R-ABS/20WF-S & $9.28 \pm 1.03^{s}$ & $2.10 \pm 0.08^{\mathrm{ns}}$ & $0.46 \pm 0.07$ & $2.36 \pm 0.50^{\mathrm{ns}}$ \\
\hline
\end{tabular}

However, as stated in previous studies [4,15,42-44], surface modification methods such as silane treatment tend to improve the interfacial adhesion between wood fibers and polymer matrices and thus result in better mechanical properties. Similar results were observed for R-ABS/20WF-S, as the tensile strength value increased by $30.33 \%$ after silane treatment. However, for R-ABS/10WF-S, the tensile strength decreased by $15 \%$ after treatment. This observation had been reported in some previous studies $[15,17,36,42,45]$. Kimchiang et al. [16] studied low-fiber-content samples, where silane concentration was above $0.5-1.5 \%$, and cases where a certain type of silane was used. The self-condensation reaction occurring on the surface of composites causes the formation of flexible polysiloxane molecules, which reduces the interfacial adhesion between treated wood fibers and matrices at low fiber contents [16]. Similarly, Chotirat et al. [15] observed that the optimum silane concentration for wood sawdust/ABS composites is around $0.5-1.0 \%$ for both low and high fiber content [15]. Furthermore, Raj et al. [45] observed that silane-treated wood/PP composites exhibit poor tensile strength and expressed that the availability of silanol groups necessary for the formation of covalent bonds was restricted by the lower surface coverage of wood fibers.

On the contrary, the tensile modulus of wood composites is usually higher than that of polymer materials and further increases as the fiber content of the composite increases $[4,15,16]$. The tensile modulus indicates the rigidity of the composite material [46]. During the experiment it was observed that tensile modulus increases by $5.8 \%$ with an increase in fiber content from 10 to $20 \%$. Later, it was observed that after silane treatment the tensile modulus of R-ABS/10WF-S and R-ABS/20WF-S increased marginally compared to the untreated recipes, indicating that silane treatment has a marginal impact on the tensile modulus of composite materials and that the modulus largely depends on the fiber. Chotirat et al. [15] observed similar observations, where the tensile modulus slightly increases in both low- and high-fiber-content samples. 
The impact strength of a polymer is influenced by the presence of a rubbery phase in the copolymer [4]. In the case of NFPCs, the impact property is dependent on many factors such as geometry, fiber arrangement, and fiber matrix interface [41]. Thus, the introduction of wood fibers reduces the toughness of the material. This is due to the restriction of polymeric chain mobility caused by the addition of wood fibers, thus reducing energy absorption capacity [4]. Further, poor interfacial adhesion causes voids in composite structure and thus leads to crack propagation during impact testing [42]. The impact strength of R-ABS/10WF was reduced by $50 \%$ in comparison to R-ABSmix and further decreased by $60 \%$ as the fiber content increased. Improvement of the impact strength of fiber-reinforced polymer composites is achieved by improving the interfacial adhesion between fiber and matrix or by adding an impact modifier that is flexible and elastic in nature [15]. However, the impact strength of R-ABS/10WF-S was $21 \%$ lower than the R-ABS/10WF composite. It is assumed that, similar to tensile strength, the reason for this decrease was the presence of an excess amount of silane concentration during fiber treatment. For higher fiber contents, silane treatment can improve the bonding between fibers and matrices, thus reducing voids and cracks [42]. As observed for R-ABS/20WF-S, the impact strength increased by about $5 \%$ in comparison with R-ABS/20WF.

\subsection{Palmyra Fiber Composites}

Table 5 shows the effect of silane and fiber content on the mechanical properties of the palmyra-fiber-reinforced composites. After statistical analysis, it was observed that the tensile strength and impact strength of both $10 \%$ and $20 \%$ untreated palm fiber composites and the tensile strength of silane-treated palm composites exhibit statistically significant changes. Meanwhile there were no significant changes observed in the tensile modulus of all the palm composite recipes. Finally, the impact strength of $10 \%$-silanetreated palm fiber composites displays significant change, while no significant change was seen in $20 \%$-silane-treated palm fiber composites. Similar to the wood fiber composites, the introduction of untreated palmyra fiber into the polymer matrix causes the tensile strength to decrease drastically and further decrease with an increase in fiber content $[2,41,47]$. However, in contrast to R-ABS/10WF-S, the introduction of silane into the composite causes the tensile strength of the R-ABS/10PF-S composite to drastically increase by $60.38 \%$. In addition, the tensile strength for R-ABS/20PF-S also increases by $41.55 \%$ after silane treatment. Similar observations were found in previous palmyra- and other palm-fiberrelated studies $[26,46,48]$. It is assumed that palmyra fibers, even at low fiber content, react to silane solution in a positive manner, and no self-condensation process takes place. Thus, even at a higher silane concentration with low palmyra fiber content, the interfacial adhesion between fibers and matrices improves. Additionally, it can also be assumed that the surface coverage of palmyra fibers was better than wood fibers, which does not restrict the availability of the silanol group for the formation of covalent bonds.

Table 5. Mechanical properties of the palmyra fiber composites and R-ABSmix.

\begin{tabular}{ccccc}
\hline & $\begin{array}{c}\text { Tensile Strength } \\
\mathbf{( M P a )}\end{array}$ & $\begin{array}{c}\text { Tensile } \\
\text { Modulus (GPa) }\end{array}$ & $\begin{array}{c}\text { Elongation at } \\
\text { Break (\%) }\end{array}$ & $\begin{array}{c}\text { Impact Strength } \\
\mathbf{( k J / \mathbf { m } ^ { 2 } )}\end{array}$ \\
\hline R-ABSmix & $16.42 \pm 1.20$ & $1.79 \pm 0.07$ & $1.00 \pm 0.19$ & $5.98 \pm 0.92$ \\
R-ABS/10PF & $6.26 \pm 1.97^{\mathrm{s}}$ & $1.82 \pm 0.34^{\mathrm{ns}}$ & $0.41 \pm 0.12$ & $2.27 \pm 0.52^{\mathrm{s}}$ \\
R-ABS/10PF-S & $10.04 \pm 2.79^{\mathrm{s}}$ & $1.92 \pm 0.12^{\mathrm{ns}}$ & $0.76 \pm 0.20$ & $3.12^{\mathrm{s}} \pm 0.87^{\mathrm{s}}$ \\
R-ABS/20PF & $6.04 \pm 1.83^{\mathrm{s}}$ & $1.88 \pm 0.13^{\mathrm{ns}}$ & $0.48 \pm 0.27$ & $2.41 \pm 0.67^{\mathrm{s}}$ \\
R-ABS/20PF-S & $8.55 \pm 0.74^{\mathrm{s}}$ & $2.00 \pm 0.10^{\mathrm{ns}}$ & $0.52 \pm 0.13$ & $2.47 \pm 0.63^{\mathrm{ns}}$ \\
\hline s, ns statistically significant and no significant changes with a 95\% confidence level, respectively.
\end{tabular}

As with wood fiber composites, the tensile modulus increases with an increase in fiber content in the composite material. It was observed that tensile modulus increases by $3.3 \%$ with an increase in fiber content. After silane treatment, tensile modulus values increase by $5.5 \%$ and $6.3 \%$ for R-ABS/10PF-S and R-ABS/20PF-S, respectively, compared to untreated composite recipes. The impact strength of composites decreased when the 
fibers were introduced; this is mainly because of the poor wetting of fibers by the polymer matrix [49]. However, in contrast to wood fibers, the impact strength of untreated palmyra fiber composites increased slightly as the palmyra fiber content increased. Similar results were seen in a previous study [47]. Furthermore, after silane treatment, the impact strength for both R-ABS/10PF-S and R-ABS/20PF-S composites increased by $37.45 \%$ and $2.5 \%$, respectively. Similar observations were reported in previous studies related to palmyra fibers $[49,50]$.

\subsection{Morphological Investigations}

In order to further understand the effect of silane treatment, the tensile-fractured surfaces of both wood and palmyra fiber composite specimens were examined with an SEM. Figure 5 shows the surface morphologies of (a) R-ABS/10WF, (b) R-ABS/10WF-S, (c) R-ABS/20WF, and (d) R-ABS/20WF-S. From the untreated material sample images, it is visible that due to the presence of voids, pullout fibers, and poor agglomeration of fibers throughout the polymer matrix, the material property of the composite materials decreases. This also confirms the incompatibility of fiber and polymer materials in the composite. However, after silane treatment for both $10 \%$ and $20 \%$ wood fiber content, the surface was found to be slightly more homogeneous, especially for R-ABS/20WF-S, thereby leading to an improvement in the tensile strength value. Finally, the presence of a high silane concentration relative to fiber content in R-ABS/10WF-S causes the tensile strength to decrease.
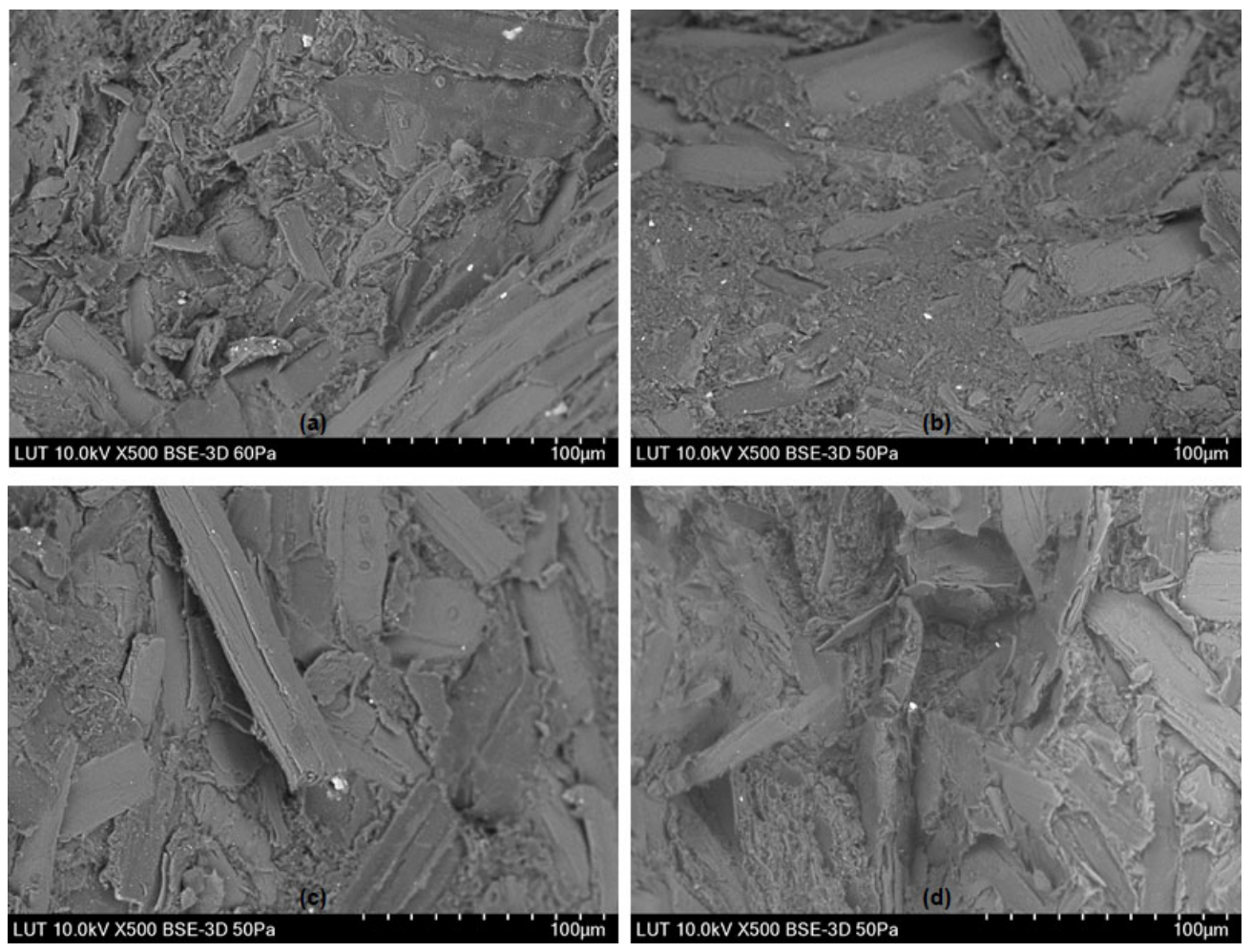

Figure 5. SEM images of wood-fiber-reinforced composites (a) R-ABS/10WF; (b) R-ABS/10WF-S; (c) R-ABS/20WF; and (d) R-ABS/20WF-S.

Figure 6 shows the surface morphologies of (a) R-ABS/10PF, (b) R-ABS/10PF-S, (c) $\mathrm{R}-\mathrm{ABS} / 20 \mathrm{PF}$, and (d) R-ABS/20PF-S. For untreated palmyra fiber composites, the presence of large voids, pullout fibers, and porous fiber structures caused the tensile strength of $\mathrm{R}-\mathrm{ABS} / 10 \mathrm{PF}$ and R-ABS/20PF to decrease. However, the introduction of silane treatment to both $10 \%$ and $20 \%$ fiber content composites saw a drastic increase in tensile strength. This is also visible in the somewhat homogenous mixture for both R-ABS/10PF-S and 
R-ABS/20PF-S; thus, adding silane improves the interfacial adhesion between fibers and polymer matrices.
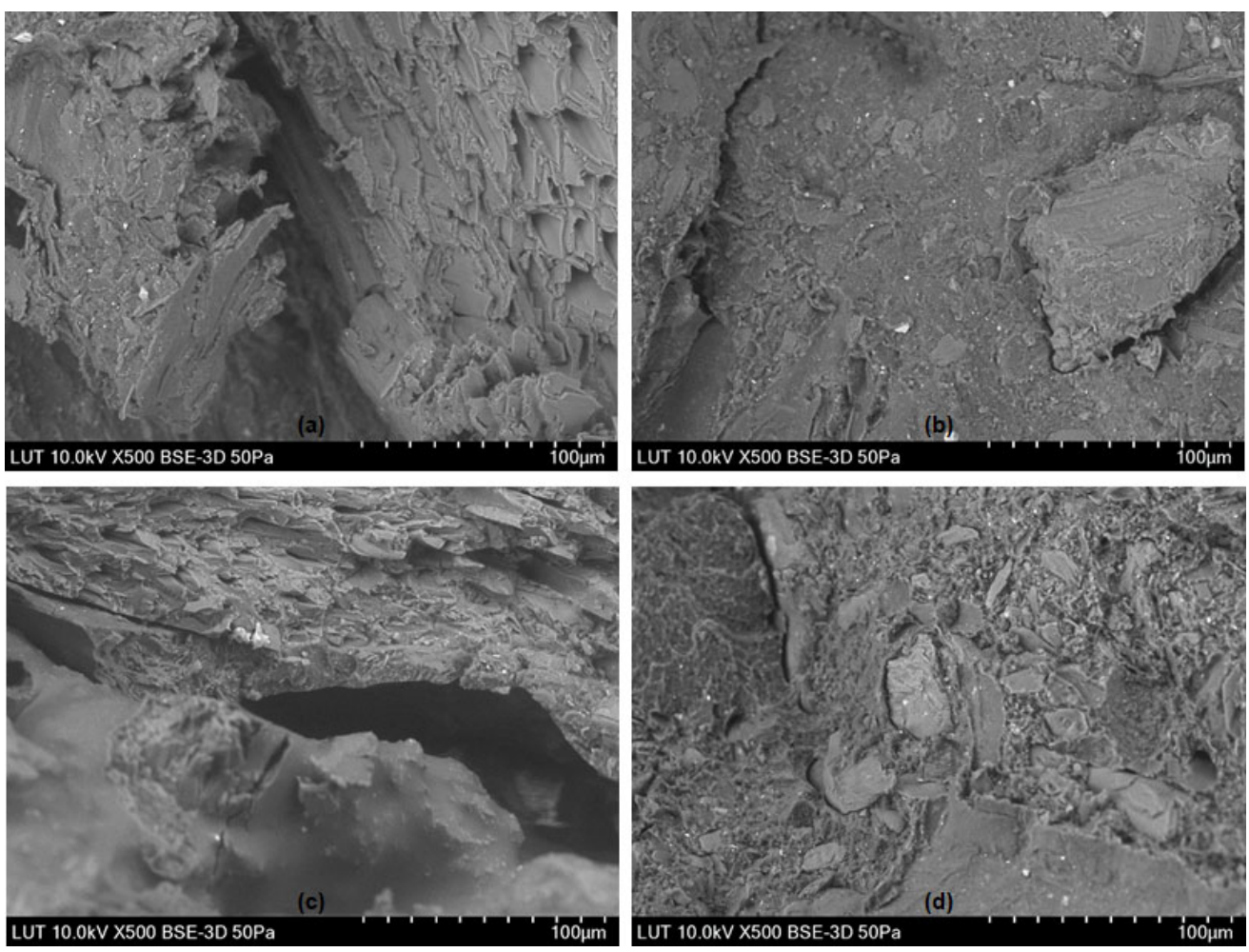

Figure 6. SEM images of palmyra-fiber-reinforced composites (a) R-ABS/10PF; (b) R-ABS/10PF-S; (c) R-ABS/20PF; and (d) R-ABS/20PF-S.

\section{Conclusions}

This study investigated the effect of fiber content and silane treatment on the mechanical properties of recycled ABS composites containing wood and palmyra fibers. Tensile and impact properties of the composite samples were examined. For the wood fiber composites, the tensile strength and impact strength decrease with an increase in fiber content. After silane treatment, the tensile strength for $20 \%$ wood fiber content increases due to improved interfacial adhesion between wood fibers and the polymer matrix. However, for $10 \%$ wood fiber content the tensile strength decreases after silane treatment due to the relatively high concentration of silane used, which results in a self-condensation reaction occurring on the surface of the composite, causing the formation of polysiloxane molecules, further negatively affecting the fiber and matrix bonding. The tensile modulus of untreated wood fiber composites increases with an increase in fiber content in the composite. Further, it was observed that silane treatment has a marginal positive effect on the tensile modulus values for both $10 \%$ and $20 \%$ wood fiber composite recipes. Similarly, tensile strength decreases with an increase in palmyra fiber content. However, after silane treatment the tensile strength increases for both $10 \%$ and $20 \%$ palmyra fiber contents. This indicates no self-condensation reaction occurring on the surface of the composite for $10 \%$ palmyra fiber content. Similar to wood fiber composites, the tensile modulus of the palmyra fiber composite increases as the fiber content increases. After silane treatment, the tensile modulus value for both $10 \%$ and $20 \%$ palmyra fiber contents increase slightly, further indicating the marginal effect of silane on the tensile modulus values of NFPCs. In contrast to wood fibers, the impact strength of the untreated palmyra fiber composites increases with an increase in fiber content. In addition, after silane treatment the impact strength of both the $10 \%$ and $20 \%$ palmyra fiber composites increases further, indicating improved interfacial bonding between fiber and matrix. The morphological analysis of both wood and palmyra fiber composites showed 
that surfaces of silane-treated composite specimens were more homogenous with fewer voids and pullout fibers compared to untreated composite specimens. Further, the presence of a relatively high concentration of silane in the composite with respect to fiber content causes certain specimens' properties to deteriorate. Considering the relatively low quality of the recycled materials, the properties of R-ABSmix and natural fiber composites were at an acceptable level, especially for the tensile modulus, which indicates high stiffness of the material. For further research, a proposal could be made to identify applications of this recycled material composite.

Author Contributions: Conceptualization, V.C., T.K. and J.V.; methodology, V.C.; validation, V.C.; formal analysis, V.C.; data curation, V.C.; investigation, V.C.; writing—original draft preparation, V.C.; writing-review and editing, V.C., T.K. and J.V; visualization, V.C.; supervision, T.K. and J.V. All authors have read and agreed to the published version of the manuscript.

Funding: This research received no external funding.

Conflicts of Interest: The authors declare no conflict of interest.

Sample Availability: Samples of the compounds are not available from the authors.

\section{References}

1. Arslan, C.; Dogan, M. The effects of fiber silane modification on the mechanical performance of chopped basalt fiber/ABS composites. J. Thermoplast. Compos. Mater. 2020, 33, 1449-1465. [CrossRef]

2. Neher, B.; Bhuiyan, M.M.R.; Kabir, H.; Qadir, M.R.; Gafur, M.A.; Ahmed, F. Study of Mechanical and Physical Properties of Palm Fiber Reinforced Acrylonitrile Butadiene Styrene Composite. Mater. Sci. Appl. 2014, 5, 39-45. [CrossRef]

3. Nikmatin, S.; Syafiuddin, A.; Irwanto, D.A.Y. Properties of Oil Palm Empty Fruit Bunch-Filled Recycled Acrylonitrile Butadiene Styrene Composites: Effect of Shapes and Filler Loadings with Random Orientation. BioResources 2016, 12, 1090-1101. [CrossRef]

4. Threepopnatkul, P.; Teppinta, W.; Sombatsompop, N. Effect of co-monomer ratio in ABS and wood content on processing and properties in wood/ABS composites. Fibers Polym. 2011, 12, 1007-1013. [CrossRef]

5. Platt, D.K. Engineering and High Performance Plastics Market Report; Smithers Rapra Technology: Birmingham, UK, 2003.

6. Margolis, J.M. Engineering Plastics Handbook; McGraw-Hill: New York, NY, USA, 2006; ISBN 9780071457675.

7. Ma, L.; He, H.; Jiang, C.; Zhou, L.; Luo, Y.; Jia, D. Effect of Alkali Treatment on Structure and Mechanical Properties of Acrylonitrile-Butadiene-Styrene/Bamboo Fiber Composites. J. Macromol. Sci. Part B Phys. 2012, 51, 2232-2244. [CrossRef]

8. Suryadi, G.S.; Nikmatin, S.; Sudaryanto; Irmansyah; Sukaryo, S.G. Surface free energy analysis of oil palm empty fruit bunches fiber reinforced biocomposites. IOP Conf. Ser. Earth Environ. Sci. 2017, 65, 012044. [CrossRef]

9. Ashby, M.F. Material profiles. In Materials and the Environment, 2nd ed.; Ashby, M.F., Ed.; Butterworth-Heinemann: Boston, MA, USA, 2013; pp. 459-595.

10. Naik, T.R.; Singh, S.S.; Huber, C.O.; Brodersen, B.S. Use of post-consumer waste plastics in cement-based composites. Cem. Concr. Res. 1996, 26, 1489-1492. [CrossRef]

11. Ismail, Z.Z.; AL-Hashmi, E.A. Use of waste plastic in concrete mixture as aggregate replacement. Waste Manag. 2008, 28, 2041-2047. [CrossRef]

12. Marzouk, O.Y.; Dheilly, R.M.; Queneudec, M. Valorization of post-consumer waste plastic in cementitious concrete composites. Waste Manag. 2007, 27, 310-318. [CrossRef]

13. Kuo, P.-Y.; Wang, S.-Y.; Chen, J.-H.; Hsueh, H.-C.; Tsai, M.-J. Effects of material compositions on the mechanical properties of wood-plastic composites manufactured by injection molding. Mater. Des. 2009, 30, 3489-3496. [CrossRef]

14. Farsi, M. Thermoplastic Matrix Reinforced with Natural Fibers: A Study on Interfacial Behavior. In Some Critical Issues for Injection Molding; Wang, J., Ed.; IntechOpen: Rijeka, Croatia, 2012; pp. 225-250.

15. Chotirat, L.; Chaochanchaikul, K.; Sombatsompop, N. On adhesion mechanisms and interfacial strength in acrylonitrilebutadiene-styrene/wood sawdust composites. Int. J. Adhes. Adhes. 2007, 27, 669-678. [CrossRef]

16. Kimchiang, P.; Threepopnatkul, P.; Sombatsompop, N. Influence of Functionalized silanes on Mechanical Properties of Wood Sawdust Reinforced ABS Composites. In Proceedings of the Processing and Fabrication of Advanced Materials XIX, Auckland, New Zealand, 14-17 January 2011; pp. 998-1005.

17. Threepopnatkul, P.; Krachang, T.; Teerawattananon, W.; Suriyaphaparkorn, K.; Kulsetthanchalee, C. Study of surface treatment of pineapple leaf fiber (PALF) on performance of PALF/ABS composites. In Proceedings of the 15th European Conference on Composite Materials, Venice, Italy, 24-28 June 2012; pp. 1-7.

18. Anandjiwala, R.D.; Blouw, S. Composites from bast fibres-Prospects and potential in the changing market environment. J. Nat. Fibers 2007, 4, 91-901. [CrossRef]

19. Holbery, J.; Houston, D. Natural-fiber-reinforced polymer composites in automotive applications. J. Miner. Met. Mater. Soc. 2006, 58, 80-86. [CrossRef] 
20. Yeh, S.K.; Agarwal, S.; Gupta, R.K. Wood-plastic composites formulated with virgin and recycled ABS. Compos. Sci. Technol. 2009, 69, 2225-2230. [CrossRef]

21. Liang, R.; Gupta, R.K. The effect of residual impurities on the rheological and mechanical properties of engineering polymers separated from mixed plastics. In Proceedings of the SPE 59th Annual Technical Conference, Dallas, TX, USA, 6-10 May 2001; pp. $2753-2757$.

22. Liang, R.; Gupta, R.K. Processing and characterization of recycled PC/ABS blends with high recycle content. In Proceedings of the SPE 60th Annual Technical Conference, San Francisco, CA, USA, 10-15 June 2002; pp. 2948-2952.

23. Chauhan, V.; Kärki, T.; Varis, J. Review of natural fiber-reinforced engineering plastic composites, their applications in the transportation sector and processing techniques. J. Thermoplast. Compos. Mater. 2019. [CrossRef]

24. Thiruchitrambalam, M.; Logesh, M.; Shanmugam, D.; Muthukumar, S. The physical, chemical properties of untreated and chemically treated palmyra palm leaf fibres. Int. J. Eng. Technol. 2018, 7, 582-585.

25. Nwabanne, J.; Igbokwe, P.; Ezeonyebuchi, E. Effect of palmyra palm fiber filler on properties of natural rubber vulcanizate. World J. Eng. 2014, 11, 565-574. [CrossRef]

26. Reddy, K.O.R.; Maheswari, C.U.; Reddy, K.O.R.; Shukla, M.; Muzenda, E.; Rajulu, A.V. Effect of Chemical Treatment and Fiber Loading on Mechanical Properties of Borassus (Toddy Palm) Fiber/Epoxy Composites. Int. J. Polym. Anal. Charact. 2015, $20,612$. [CrossRef]

27. Räisänen, T.; Athanassiadis, D. Basic Chemical Composition of the Biomass Components of Pine, Spruce and Birch. Available online: http:/ / www.biofuelregion.se/UserFiles / file/Forest\%20Refine/1_2_IS_2013-01-31_Basic_chemical_composition.pdf (accessed on 25 October 2021).

28. Wang, Q.; Zhang, Y.; Liang, W.; Wang, J.; Chen, Y. Effect of silane treatment on mechanical properties and thermal behavior of bamboo fibers reinforced polypropylene composites. J. Eng. Fiber. Fabr. 2020, 15, 1558925020958195. [CrossRef]

29. Rehman, M.M.; Zeeshan, M.; Shaker, K.; Nawab, Y. Effect of micro-crystalline cellulose particles on mechanical properties of alkaline treated jute fabric reinforced green epoxy composite. Cellulose 2019, 26, 9057-9069. [CrossRef]

30. Bledzki, A.; Al-Mamun, D.A.; Lucka-Gabor, M.M.; Gutowski, V. The effects of acetylation on properties of flax fibre and its polypropylene composites. eXPRESS Polym. Lett. 2008, 2, 413-422. [CrossRef]

31. De Prez, J.; Van Vuure, A.W.; Ivens, J.; Aerts, G.; Van de Voorde, I. Enzymatic treatment of flax for use in composites. Biotechnol. Rep. (Amst. Neth.) 2018, 20, e00294. [CrossRef] [PubMed]

32. Uehara, T.; Sakata, I. Effect of corona discharge treatment on cellulose prepared from beech wood. J. Appl. Polym. Sci. 1990, 41, 1695-1706. [CrossRef]

33. Sèbe, G.; Brook, M.A. Hydrophobization of wood surfaces: Covalent grafting of silicone polymers. Wood Sci. Technol. 2001, 35, 269-282. [CrossRef]

34. Ali, A.; Shaker, K.; Nawab, Y.; Jabbar, M.; Hussain, T.; Militky, J.; Baheti, V. Hydrophobic treatment of natural fibers and their composites-A review. J. Ind. Text. 2016, 47, 2153-2183. [CrossRef]

35. Väntsi, O.; Kärki, T. Different coupling agents in wood-polypropylene composites containing recycled mineral wool: A comparison of the effects. J. Reinf. Plast. Compos. 2015, 34, 879-895. [CrossRef]

36. Orue, A.; Jauregi, A.; Unsuain, U.; Labidi, J.; Eceiza, A.; Arbelaiz, A. The effect of alkaline and silane treatments on mechanical properties and breakage of sisal fibers and poly(lactic acid)/sisal fiber composites. Compos. Part A Appl. Sci. Manuf. 2016, 84, 186-195. [CrossRef]

37. Neher, B.; Nova, N.; Hossain, R.; Gafur, M.; Ahmed, F. Fabrication and Characterization on Physico-Mechanical and Structural Properties of Sawdust Reinforced Acrylonitrile Butadiene Styrene (ABS) Composites. Mater. Sci. Appl. 2020, 11, 644-658. [CrossRef]

38. Martins, J.N.; Klohn, T.G.; Bianchi, O.; Fiorio, R.; Freire, E. Dynamic mechanical, thermal, and morphological study of ABS/textile fiber composites. Polym. Bull. 2010, 64, 497-510. [CrossRef]

39. Demir, H.; Atikler, U.; Balköse, D.; Tihminlioğlu, F. The effect of fiber surface treatments on the tensile and water sorption properties of polypropylene-luffa fiber composites. Compos. Part A Appl. Sci. Manuf. 2006, 37, 447-456. [CrossRef]

40. Xie, Y.; Hill, C.A.S.; Xiao, Z.; Militz, H.; Mai, C. Silane coupling agents used for natural fiber/polymer composites: A review. Compos. Part A Appl. Sci. Manuf. 2010, 41, 806-819. [CrossRef]

41. Velmurugan, R.; Manikandan, V. Mechanical properties of palmyra/glass fiber hybrid composites. Compos. Part A Appl. Sci. Manuf. 2007, 38, 2216-2226. [CrossRef]

42. Kim, T.-W.; Lee, S.-Y.; Chun, S.-J.; Doh, G.-H.; Paik, K.-H. Effect of silane coupling on the fundamental properties of wood flour reinforced polypropylene composites. J. Compos. Mater. 2011, 45, 1595-1605. [CrossRef]

43. Lv, S.; Tan, H.; Gu, J.; Zhang, Y. Silane Modified Wood Flour Blended with Poly(lactic acid) and its Effects on Composite Performance. BioResources 2015, 10, 5426-5439. [CrossRef]

44. Zhou, L.; Guo, C.; Li, L. Influence of ammonium polyphosphate modified with 3-(methylacryloxyl) propyltrimethoxy silane on mechanical and thermal properties of wood flour-polypropylene composites. J. Appl. Polym. Sci. 2011, 122, 849-855. [CrossRef]

45. Raj, R.G.; Kokta, B.V.; Daneault, C. Polypropylene-Wood Fiber Composites: Effect of Fiber Treatment on Mechanical Properties. Int. J. Polym. Mater. Polym. Biomater. 1989, 12, 239-250. [CrossRef] 
46. Eng, C.C.; Ibrahim, N.; Zainuddin, N.; Ariffin, H.; Yunus, W. Chemical Modification of Oil Palm Mesocarp Fiber by Methacrylate Silane: Effects on Morphology, Mechanical, and Dynamic Mechanical Properties of Biodegradable Hybrid Composites. Bioresources 2015, 11, 861-872. [CrossRef]

47. Srinivasababu, N.; Kumar, J.S.; Reddy, K.V.K. Mechanical and Dielectric Properties of PTSL FRP Composites. Adv. Mater. Res. 2012, 585, 311-316. [CrossRef]

48. Atiqah, A.; Jawaid, M.; Jawaid, M.; Ishak, M.R.; Sapuan, S.M.; Sapuan, S.M. Effect of Alkali and Silane Treatments on Mechanical and Interfacial Bonding Strength of Sugar Palm Fibers with Thermoplastic Polyurethane. J. Nat. Fibers 2018, 15, $251-261$. [CrossRef]

49. Abu Bakar, A.; Hassan, A.; Mohd Yusof, A.F. Mechanical Properties of Silane and Zirconate Coupling Agent-Treated Oil Palm Empty Fruit Bunch Fiber-Filled Acrylic-Impact Modified Poly (Vinyl Chloride) Composites. Polym. Plast. Technol. Eng. 2010, 49, 1563-1570. [CrossRef]

50. Nnaemeka, A.A.; Kamardeen, A.O. Effect of Silane Treatment on the Impact Strength Properties of Oil Palm Empty Fruit Bunch Fiber-Reinforced Polyester Composites. World J. Eng. Pure Appl. Sci. 2011, 1, 40. 